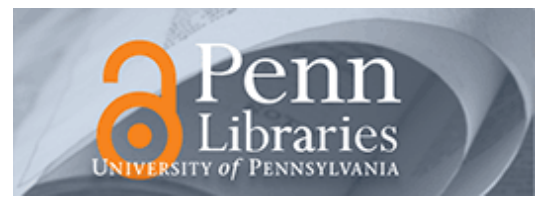

University of Pennsylvania

ScholarlyCommons

\title{
Stretch Magnitude and Frequency-Dependent Actin Cytoskeleton Remodeling in Alveolar Epithelia
}

\author{
Brian Christopher DiPaolo \\ University of Pennsylvania, bdipaolo@seas.upenn.edu \\ Guillaume Lenormand, \\ Jeffrey J. Fredberg \\ Susan S. Margulies \\ University of Pennsylvania, margulies@seas.upenn.edu
}

Follow this and additional works at: https://repository.upenn.edu/be_papers

Part of the Biomedical Engineering and Bioengineering Commons, and the Cellular and Molecular Physiology Commons

\section{Recommended Citation}

DiPaolo, B. C., Lenormand,, G., Fredberg, J. J., \& Margulies, S. S. (2010). Stretch Magnitude and FrequencyDependent Actin Cytoskeleton Remodeling in Alveolar Epithelia. American Journal of Physiology - Cell Physiology, 299 (2), C345-C353. http://dx.doi.org/10.1152/ajpcell.00379.2009 


\title{
Stretch Magnitude and Frequency-Dependent Actin Cytoskeleton Remodeling in Alveolar Epithelia
}

\begin{abstract}
Alveolar epithelial cells (AEC) maintain integrity of the blood-gas barrier with gasket-like intercellular tight junctions (TJ) that are anchored internally to the actin cytoskeleton. We hypothesize that stretch rapidly reorganizes actin ( $<10>\mathrm{min})$ into a perijunctional actin ring (PJAR) in a manner that is dependent on magnitude and frequency of the stretch, accompanied by spontaneous movement of actin-anchored receptors at the plasma membrane. Primary AEC monolayers were stretched biaxially to create a change in surface area $(\triangle S A)$ of $12 \%, 25 \%$, or $37 \%$ in a cyclic manner at $0.25 \mathrm{~Hz}$ for up to $60 \mathrm{~min}$, or held tonic at $25 \% \triangle S A$ for up to 60 min, or left unstretched. By 10 min of stretch PJARs were evident in $25 \%$ and $37 \%$ $\Delta S A$ at $0.25 \mathrm{~Hz}$, but not for $12 \% \Delta S A$ at $0.25 \mathrm{~Hz}$, or at tonic $25 \% \Delta S A$, or with no stretch. Treatment with 1 $\mu \mathrm{M}$ jasplakinolide abolished stretch-induced PJAR formation, however. As a rough index of remodeling rate, we measured spontaneous motions of $5-\mu \mathrm{m}$ microbeads bound to actin focal adhesion complexes on the apical membrane surfaces; within 1 min of exposure to $\Delta S A$ of $25 \%$ and $37 \%$, these motions increased substantially, increased with increasing stretch frequency, and were consistent with our mechanistic hypothesis. With a tonic stretch, however, the spontaneous motion of microbeads attenuated back to unstretched levels, whereas PJAR remained unchanged. Stretch did not increase spontaneous microbead motion in human alveolar epithelial adenocarcinoma A549 monolayers, confirming that this actin remodeling response to stretch was a cell-type specific response. In summary, stretch of primary rat AEC monolayers forms PJARs and rapidly reorganized actin binding sites at the plasma membrane in a manner dependent on stretch magnitude and frequency.
\end{abstract}

\section{Keywords}

mean square displacement, perijunctional actomyosin ring, epithelial, lung injury, mechanical ventilation

\section{Disciplines}

Biomedical Engineering and Bioengineering | Cellular and Molecular Physiology | Engineering 


\title{
Stretch magnitude and frequency-dependent actin cytoskeleton remodeling in alveolar epithelia
}

\author{
Brian C. DiPaolo, Guillaume Lenormand, [...], and Susan S. Margulies
}

\section{Abstract}

Alveolar epithelial cells (AEC) maintain integrity of the blood-gas barrier with gasket-like intercellular tight junctions (TJ) that are anchored internally to the actin cytoskeleton. We hypothesize that stretch rapidly reorganizes actin ( $<10 \mathrm{~min})$ into a perijunctional actin ring (PJAR) in a manner that is dependent on magnitude and frequency of the stretch, accompanied by spontaneous movement of actinanchored receptors at the plasma membrane. Primary AEC monolayers were stretched biaxially to create a change in surface area $(\Delta \mathrm{SA})$ of $12 \%, 25 \%$, or $37 \%$ in a cyclic manner at $0.25 \mathrm{~Hz}$ for up to $60 \mathrm{~min}$, or held tonic at $25 \% \Delta \mathrm{SA}$ for up to $60 \mathrm{~min}$, or left unstretched. By 10 min of stretch PJARs were evident in $25 \%$ and $37 \% \Delta \mathrm{SA}$ at $0.25 \mathrm{~Hz}$, but not for $12 \% \Delta \mathrm{SA}$ at $0.25 \mathrm{~Hz}$, or at tonic $25 \% \Delta \mathrm{SA}$, or with no stretch. Treatment with $1 \mu \mathrm{M}$ jasplakinolide abolished stretch-induced PJAR formation, however. As a rough index of remodeling rate, we measured spontaneous motions of $5-\mu \mathrm{m}$ microbeads bound to actin focal adhesion complexes on the apical membrane surfaces; within 1 min of exposure to $\Delta \mathrm{SA}$ of $25 \%$ and $37 \%$, these motions increased substantially, increased with increasing stretch frequency, and were consistent with our mechanistic hypothesis. With a tonic stretch, however, the spontaneous motion of microbeads attenuated back to unstretched levels, whereas PJAR remained unchanged. Stretch did not increase spontaneous microbead motion in human alveolar epithelial adenocarcinoma A549 monolayers, confirming that this actin remodeling response to stretch was a cell-type specific response. In summary, stretch of primary rat AEC monolayers forms PJARs and rapidly reorganized actin binding sites at the plasma membrane in a manner dependent on stretch magnitude and frequency.

Keywords: mean square displacement, perijunctional actomyosin ring, epithelial, lung injury, mechanical ventilation

MECHANICAL VENTILATION is vital for treating specific life-threatening conditions but has been implicated in the etiology of pulmonary barrier dysfunction. Ventilator-induced lung injury occurs in 5 to $15 \%$ of patients requiring mechanical ventilation $(41,65)$ and has a mortality rate of $34-60 \%$ in those patients with acute respiratory distress syndrome (21). During mechanical ventilation, pulmonary alveolar epithelial cells (AEC) undergo biaxial stretch as the surface of the basement membrane increases (55), but the delivery of large gas volumes to localized lung regions has been implicated in the increase of blood-gas barrier permeability (19, 27). Previously, rat type 1like AEC monolayers in culture were used to mimic the alveolar epithelium in vitro (4, 12, 15, 30, 39). Cavanaugh and Margulies (10) demonstrated that high biaxial stretch ( $37 \%$ change in surface area, $\Delta \mathrm{SA})$, analogous to pathological ventilator volumes, results in an increase in paracellular permeability where tight junctions (TJ) offer primary resistance to epithelial paracellular transport (37). Investigators have demonstrated an integral role of the actin cytoskeleton in cell-cell adhesion (61) and anchoring TJ protein (32) in other cell types. Others have shown that disruption of filamentous actin (F-actin) perturbs $\mathrm{TJ}$ functionality as a mediator of paracellular permeability as well as TJ structure $(11,33)$. Moreover, cyclic stretch has been shown to alter F-actin distribution in alveolar epithelial cells (36). Taken together, these results lead to our hypothesis that during biaxial stretch the actin cytoskeleton has an integral effect on TJ-mediated paracellular permeability.

When a cell is stretched, the cell transduces the mechanical signal into a cascade of biochemical signals $(16,66)$ resulting in actin cytoskeleton rearrangement. During uniaxial stretch, F-actin cross-links with myosin and numerous actin-binding proteins to form thick polymerized bundles or actin stress fibers. Human pulmonary artery endothelial cells (HPAEC) cyclically elongated uniaxially rapidly form actin stress fibers aligned perpendicular to stretch direction and enhanced F-actin at the cell periphery $(3,26,49,52,63)$. When endothelial and epithelial monolayers are stretched biaxially, actin reorganizes into stress fibers that form "tent-like" structures in the direction of least strain $(11,36,63)$, forming perijunctional actin rings (PJAR) or perijunctional actomyosin rings (57) composed of actin and myosin $(20,67)$. Lung cells experience biaxial loading routinely, but to date there is a paucity of data regarding the effect of biaxial stretch rate and magnitude on the actin cytoskeleton of AEC monolayers.

The goals of our study are to test whether PJAR formation and PJAR intensity are dependent on biaxial stretch magnitude, frequency, and duration and to determine whether PJAR is mechanistically related to actin dynamics in monolayers of rat type 1-like AECs. Our overall hypothesis is that actin redistributes rapidly (within $10 \mathrm{~min}$ ) such that PJAR formation and fluorescent intensity are both dependent on stretch magnitude and frequency. Our observations suggest that the actin cytoskeleton movement at the membrane increases rapidly $(<1$ min), concurrent with a PJAR formation that is dependent on stretch magnitude, frequency, and time. Even with continued stretch, actin cytoskeleton rearrangement rates slow over time, although PJAR remains. 


\section{MATERIALS AND METHODS}

Primary rat type 1-like alveolar epithelial cell isolation. Alveolar type II cells were isolated from male Sprague-Dawley rats based on a method reported by Dobbs et al. (17) with slight modification (56). The animal protocols used in this study were reviewed and approved by the University of Pennsylvania IACUC. Cells were seeded at 1.0 million cells $/ \mathrm{cm}^{2}$ onto fibronectin-coated $\left(10 \mu \mathrm{g} / \mathrm{cm}^{2}\right.$, Invitrogen, Carlsbad, CA) flexible Silastic membranes (Specialty Manufacturing, Saginaw, MI) in custom-designed wells (55). The cells were cultured for 5 days at $37^{\circ} \mathrm{C}, 5 \% \mathrm{CO}_{2}$ in MEM with $10 \%$ FBS replaced daily. After 5 days, the cells had adopted alveolar type I (ATI) features (4, 12, $14,15,39,45)$, including the expression of RTI40, and had grown to a confluent monolayer. Monolayers were then serum deprived in Dulbecco's MEM (DMEM, Mediatech, Manassas, VA) supplemented with $20 \mathrm{mM}$ HEPES for $3 \mathrm{~h}$ (unless stated otherwise) and stretched biaxially across a range of physiological relevant magnitudes including at $12 \%, 25 \%$, or $37 \% \Delta$ SA roughly corresponding to $64 \%, 86 \%$, and $100 \%$ total lung capacity, respectively (55). Because stretch rate also significantly affects the alveolar cell monolayer viability and permeability $(14,56)$, both sustained tonic and cyclic stretch modes were investigated. Sustained tonic stretch $(0 \mathrm{~Hz}$, held at stretch) was used to model alveoli held at partial (residual) inflation. Cyclic (sinusoidal) stretch $(0.25 \mathrm{~Hz})$ was used to model ventilation.

PJAR quantification. Primary rat AEC monolayers were stretched biaxially at $12 \%, 25 \%$, or $37 \% \Delta$ SA cyclically at $0.25 \mathrm{~Hz}$ for 0 (unstretched), 1, 10, or $60 \mathrm{~min}$. An additional group of monolayers were stretched at $25 \% \Delta \mathrm{SA}$ and held (sustained tonic, $0 \mathrm{~Hz}$ ) at stretch for the same durations. At the end of the stretch period, monolayers were fixed with 1.5\% paraformaldehyde (Electron Microscopy Sciences, Hatfield, PA) in phosphate-buffered saline (PBS) for 15 min, permeabilized using $0.1 \%$ Triton X-100 in PBS for 5 min, and blocked with 5\% goat serum in PBS for $1 \mathrm{~h}$. Wells were double stained (in 5\% goat serum in PBS for $1 \mathrm{~h}$ at $23^{\circ} \mathrm{C}$ ) for F-actin (phalloidin, Invitrogen, Carlsbad, CA) to evaluate PJAR and zona occludens-1 (ZO-1; anti-ZO1 antibody, Invitrogen) to identify the location of the cell plasma membrane.

Both red (F-actin) and green (ZO-1) channels of two random microscope fields from each labeled monolayer were captured ( $\times 40$ objective) on an epifluorescent scope (Nikon) using identical exposure times for all images of each type. Each field was divided into a $3 \times$ 3 matrix of regions, and every other region ( 5 regions) was systematically selected for analysis. In each region, all cells with at least $50 \%$ of its area residing in the region were evaluated, typically 16 cells per field. The perijunctional F-actin fluorescent intensity of each cell was analyzed (ImageJ, version 1.43j) by tracing the peripheral ZO-1 (see Fig. 2, top inset), superimposing this ZO-1 trace onto the same cell stained for F-actin (see Fig. 2, bottom inset) and enlarging the trace line thickness radially inward and outward to create a boundary zone for further analysis $\sim 1.6-\mu \mathrm{m}$ thick (average PJAR thickness from a small sample study, Fig. 2, bottom inset, white contours). Mean F-actin fluorescent intensity in this peripheral annulus $\left(A_{\mathrm{i}}\right)$ was measured. Whole cell F-actin mean fluorescent intensity $\left(W_{\mathrm{i}}\right)$ was determined, including annulus and cell interior. PJAR intensity $\left(P_{\mathrm{i}}\right)$ was found by taking the ratio of peripheral annulus mean intensity to whole cell mean intensity $\left(P_{\mathrm{i}}=A_{\mathrm{i}} / W_{\mathrm{i}}\right)$. For each experimental group, $P_{\mathrm{i}}$ was evaluated based on an average 32 cells ( 2 fields) per animal from at least 4 different animals. With the use of Dunnett's test with 0 min stretch (unstretched, UNS) as reference, mean $P_{\mathrm{i}}$ for each sample (monolayer) was evaluated for each stretch magnitude across time and at each time point across stretch magnitude (12, 25, 37\% $\Delta \mathrm{SA}$ ) and frequency (dynamic and tonic). Significance was defined as $P<0.05$.

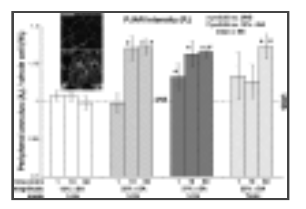

Fig. 2.

PJAR intensity $\left(P_{\mathrm{i}}\right)$ was found by taking the ratio of peripheral annulus F-actin mean intensity to whole cell F-actin mean intensity $\left(P_{\mathrm{i}}=A_{\mathrm{i}} / W_{\mathrm{i}}\right)$ and plotted as a function of stretch magnitude, time, and frequency. $P_{\mathrm{i}}$ was significantly higher than UNS ...

Actin-mediated binding site movement. Spontaneous nanoscale motions of microbeads attached to cell surface integrin receptors were monitored to assess a mechanism of the molecular scale cytoskeletal rearrangement $(2,7,8,47)$. The receptors are linked internally to the actin cytoskeleton $(2,8,53)$. Rat type 1-like AEC monolayers that had been maintained in culture for 4 days were then serum deprived overnight in DMEM + HEPES. Ferrimagnetic microbeads ( $5 \mu \mathrm{m}$ diameter, provided by Harvard School of Public Health, Boston, MA) were coated at $150 \mu \mathrm{g}$ peptide per 1-mg beads with either Arg-Gly-Asp (RGD, Sigma-Aldrich, St. Louis, MO) for adhesion to actin anchored (35) transmembrane integrin receptors $(60,64,68)$ or acetylated low-density lipoprotein (AcLDL, Invitrogen), a protein complex that binds scavenger receptors but not focal adhesion complexes, as nonspecific control $(43,44,64)$, then introduced onto cell monolayers. Adherent microbeads (see Fig. 3B, inset top and bottom) were serially imaged through a $\times 20$ objective (Nikon) at $1 \mathrm{~Hz}$ on a phase-contrast epifluorescent scope in 5-min epochs, first in monolayers at rest. The monolayers were then immediately stretched biaxially to $25 \%$ or $37 \% \Delta \mathrm{SA}$ and held (sustained tonic stretch) and imaged during stretch (5-min image acquisition, see top timeline in 
Fig. $3 A$ ). Microbeads attached to unstretched (UNS) cells imaged at the same intervals for the same duration served as controls (see bottom timeline, Fig. $3 A$ ). An additional group of rat type 1-like AEC monolayers were stretched cyclically $(0.25 \mathrm{~Hz})$ for a total of 40 min, imaged at similar intervals for $5 \mathrm{~min}$ at rest, and analyzed similarly (see middle timeline, Fig. $3 A$ ).

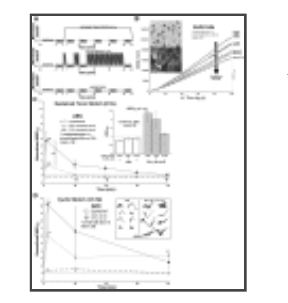

Fig. 3.

A: applied stretch protocol in monolayers held in sustained tonic stretch (top), stretched cyclically (middle), or left unstretched (bottom). Monolayers were left on the scope to equilibrate for $30 \mathrm{~min}$ before start of stretch. Stretch starts at time $=\ldots$

A separate group of monolayers were pretreated with $1 \mu \mathrm{M}$ jasplakinolide (Invitrogen) or $0.1 \mu \mathrm{M}$ latrunculin-A (Invitrogen), or DMSO as vehicle control for $10 \mathrm{~min}$ during bead incubation and then washed to free nonadherent beads and end treatment. Five to nine monolayers per group isolated from at least three rats were studied under each condition, each with an average of 125 analyzed microbeads. To compare primary AEC with the human alveolar epithelial adenocarcinoma A549 cell line (ATCC, Manassas, VA), in separate studies A549 cells seeded onto Silastic membranes at 0.25 million cells $/ \mathrm{cm}^{2}$ in $\mathrm{MEM}+10 \% \mathrm{FBS}$ at $37^{\circ} \mathrm{C}, 5 \% \mathrm{CO}_{2}$ overnight then serum deprived with DMEM + HEPES overnight grew to confluent monolayers and were held at sustained tonic stretch, and the spontaneous nanoscale motion of microbeads was analyzed.

Each 5-min (300 frames) epoch of images was analyzed by using a novel MATLAB (version 6.5 R13, The MathWorks, Natick, MA) program that determines the center of mass of each microbead, tracking it for the duration of the stretch (Fig. 3D, inset) while removing erroneous whole field displacement caused by microscope stage or Silastic membrane movement during image capture by subtracting the median $x$ and $y$ displacement components of all microbeads from the $x$ and $y$ displacement components of each microbead, respectively. Using bead coordinates, we calculated the mean square displacement (MSD) of each microbead:

$$
\operatorname{MSD}(\Delta t)=[r(t+\Delta t)-r(t)]^{2}
$$

where $r(t)$ is the microbead position at time $t$, and $\Delta t$ is the time between measurements (time lag).

When microbeads were coated with AcLDL, MSD was hypothesized to be a measure of binding site fluidity within the plasma membrane; when microbeads were coated with RGD, MSD was hypothesized to be a measure of actin remodeling within the cytoskeleton $(2,7,8,47) . M_{100}$, the total mean squared displacement over $100 \mathrm{~s}(\Delta t=100 \mathrm{~s}$, Fig. $3 B)$, of each microbead was evaluated by averaging total MSD from every $100 \mathrm{~s}$ long window of time contained within the 5-min image capture epoch (200 total windows). Median $\mathrm{MSD}_{100}$ of all microbeads in each monolayer (average of 125 analyzed microbeads per monolayer) was then calculated and used as the measure of actin binding site movement. Median was used because MSD has a lognormal distribution (7) and to remove rare, yet potentially mean confounding, erroneous bead tracks (beads attached to monolayer impurities or adjacent beads, improperly identified beads, nonadherent beads) from the sample. The median $\mathrm{MSD}_{100}$ value during stretch of each monolayer was divided by its respective median $\mathrm{MSD}_{100}$ value just before stretch ( stretch time $\left.=0 \mathrm{~min}\right)$ to determine normalized $\mathrm{MSD}_{100}\left(\mathrm{nMSD}_{100}\right)$ of the monolayer. $\mathrm{nMSD}_{100}$ was used to compare across stretch regimens, durations, and cell types. Normalization was performed at each stretch duration to standardize a sample to help account for sample-to-sample variations in initial $\mathrm{MSD}_{100}$ as result of variation in microscope stage temperature and monolayer handling.

To test the effect of stretch and treatment, $\mathrm{nMSD}_{100}$ values were compared with time-matched unstretched and untreated controls, respectively, using an ANOVA with Dunnett's test. To test the effect of stretch time, $\mathrm{nMSD}_{100}$ values were compared with their prestretch values using a Dunnetts one-way ANOVA for repeated measures.

\section{RESULTS}

PJAR formation is rapid (<10 min) and dependent on stretch magnitude and frequency. The phalloidin-stained F-actin cytoskeleton in primary rat type 1-like AEC monolayers stretched biaxially reveals qualitative evidence of PJAR by 10 min persisting up to $60 \mathrm{~min}$ in $25 \% \triangle \mathrm{SA}$ and $37 \% \Delta$ SA $0.25 \mathrm{~Hz}$ (Fig. 1A, panels 3 and 4, respectively) stretched monolayers. In contrast, UNS monolayers and monolayers stretched at $12 \% \Delta$ SA $0.25 \mathrm{~Hz}$ for $60 \mathrm{~min}$ displayed homogenous actin morphology (Fig. 1A, panels 1 and 2, respectively). Monolayers held sustained tonic stretch at $25 \% \Delta \mathrm{SA}$ reveal evidence of PJAR at $60 \mathrm{~min}$ (Fig. 1A, panel 5). For comparison with microbead tracking data, qualitative 


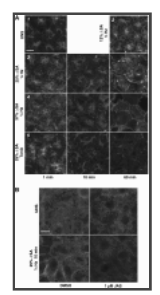

Fig. 1.

$A$ : effect of biaxial stretch duration, magnitude, and frequency on F-actin arrangement in type 1-like rat alveolar epithelial cell (AEC) monolayers before and after 1, 10, and 60 min of stretch (time on $x$-axis). 1) Monolayers left unstretched (UNS).

$\cdots$

These qualitative observations of rapid PJAR formation correlated well with the quantitative metrics. PJAR intensity $\left(P_{\mathrm{i}}\right)$ was significantly higher than UNS by $1 \mathrm{~min}$ in monolayers stretched at $37 \% \Delta \mathrm{SA} 0.25 \mathrm{~Hz}$ and by $10 \mathrm{~min}$ in monolayers stretched at $25 \% \Delta \mathrm{SA}$ $0.25 \mathrm{~Hz}$ (Fig. 2, dark grey bars and light grey bars, respectively) but was not significantly different in monolayers stretched at $12 \% \Delta \mathrm{SA}$ $0.25 \mathrm{~Hz}$ (white bars) at any time. At $60 \mathrm{~min}$ of stretch, $P_{\mathrm{i}}$ was significantly higher in monolayers stretched at $37 \% \Delta \mathrm{SA} 0.25 \mathrm{~Hz}$ and $25 \%$ $\Delta$ SA tonic and $0.25 \mathrm{~Hz}$ compared with both $12 \% \Delta \mathrm{SA} 0.25 \mathrm{~Hz}$ and UNS. Thus $P_{\mathrm{i}}$ showed a dependence on both stretch magnitude and stretch frequency.

We hypothesized that actin cytoskeleton remodeling during formation of PJAR in stretched AEC monolayers would be accompanied by an increase in the movement of microbeads coated with the Arg-Gly-Asp (RGD) peptide sequence specifically binding to apical cell surface transmembrane integrin receptors that anchor to the cytoskeleton. Qualitative PJAR formation data corroborates well with microbead tracking data, showing significant actin remodeling in $25 \%$ and $37 \% \Delta$ SA tonic $(0 \mathrm{~Hz})$ and dynamic $(0.25 \mathrm{~Hz})$ stretched monolayers after 1 min (Fig. 3, $C$ and $D$, respectively). Also, similar to quantitative $P_{\mathrm{i}}$ data, the microbeads adhered to the RGD receptors showed an effect of stretch magnitude and frequency at $1 \mathrm{~min}$ of stretch, such that $\mathrm{nMSD}_{100}$ (mean squared displacement during $100 \mathrm{~s}$ normalized to unstretched values) was significantly higher in both $25 \%$ and $37 \% \Delta$ SA held (sustained tonic) stretched (Fig. $3 C$ ) and cyclic $(0.25 \mathrm{~Hz}$ ) stretched monolayers (Fig. 3D) compared with their unstretched values. Furthermore, at 1 min stretch nMSD 100 was even greater in $37 \%$ $\Delta \mathrm{SA}$ sustained tonic compared with $25 \% \Delta \mathrm{SA}$ sustained tonic (Fig. 3C). Finally, at $1 \mathrm{~min} \mathrm{nMSD}_{100}$ was greater in $25 \% \Delta \mathrm{SA} 0.25 \mathrm{~Hz}$ when compared with $25 \% \Delta \mathrm{SA}$ sustained tonic stretch (Fig. 3, $D$ vs. $C$ ). Thus actin movement at the cell membrane significantly increased at $1 \mathrm{~min}$ of stretch compared with the unstretched time point and, similar to $P_{\mathrm{i}}$, was sensitive to stretch magnitude and frequency.

Although qualitative images and quantitative PJAR formation showed PJAR persistence for stretch duration, the spontaneous movement of anchored RGD-coated microbeads dropped precipitously after $1 \mathrm{~min}$, back to prestretch levels for all stretch conditions (Fig. 3, $C$ and $D$ ). The one exemption was at $40 \mathrm{~min}$ in the $25 \% \Delta \mathrm{SA} 0.25-\mathrm{Hz}$ stretched monolayer group where $\mathrm{nMSD}_{100}$ was also higher than unstretched at this time point. Also, at longer stretch durations ( $\geq 10-40 \mathrm{~min}$ ), spontaneous microbead movement showed no dependence on stretch magnitude. Finally, $\mathrm{nMSD}_{100}$ in unstretched monolayers significantly decreased by 10 min, remaining constant (except at 30 min, which was not different from time $=0$ ) for the duration of time in the sustained tonic group, but not in the cyclic group.

Stretch-induced PJAR formation can be inhibited with jasplakinolide and latrunculin-A. Treatment with jasplakinolide was used to stabilize the actin cytoskeleton $(5,6)$. Monolayers treated with $1 \mu \mathrm{M}$ jasplakinolide for $10 \mathrm{~min}$ and then stretched $25 \% \Delta \mathrm{SA} 0.25 \mathrm{~Hz}$ showed no qualitative evidence of PJAR formation when fixed and labeled with F/G-actin antibody (Fig. 1B, bottom right). For comparison, consider monolayers stretched at the same magnitude and duration with vehicle control (Fig. 1B, bottom left).

Qualitative images showing inhibited PJAR formation with jasplakinolide treatment corroborated well with quantitative measures of microbead tracking data. Treatment with $1 \mu \mathrm{M}$ jasplakinolide for $10 \mathrm{~min}$ also significantly attenuates the movement of integrin-adhered microbeads $\left(\mathrm{MSD}_{100}\right.$ of 2,962 $\left.\pm 360 \mathrm{~nm}^{2} \mathrm{SE}\right)$ when compared with untreated monolayers at the same $\left(\mathrm{MSD}_{100}\right.$ of $\left.5,891 \pm 743 \mathrm{~nm}^{2} \mathrm{SE}\right)$. Thus we conclude actin stabilization with jasplakinolide pretreatment inhibits actin binding site movement and formation of PJAR in stretched monolayers.

Hypothesizing that actin reorganization requires depolymerization (inhibited by jasplakinolide) and repolymerization, we used latrunculinA to inhibit actin repolymerization (70) in stretched monolayers. Monolayers exposed to (sustained tonic) stretch of $25 \% \Delta \mathrm{SA}, 0.1 \mu \mathrm{M}$ latrunculin-A pretreatment attenuated the rapid ( $<1 \mathrm{~min})$ increase in the spontaneous movement of microbeads attached to integrin receptors (Fig. 3C, inset) found in untreated monolayers. Thus pretreatment with latrunculin-A abolished stretch-induced actin binding site remodeling. 
Actin remodeling response depends on cell type. Primary rat type 1-like AEC monolayer behavior was compared with monolayers of a human alveolar epithelial adenocarcinoma A549 cell line (29). Qualitatively, A549 monolayers labeled with phalloidin for F-actin exhibit PJAR in both unstretched and held (sustained tonic) stretch of 37\% $\Delta \mathrm{SA}$ for up to $40 \mathrm{~min}$ (Fig. 4, inset). Thus A549 cells display no stretchinduced actin remodeling. Similarly, A549 monolayers held stretched at 25\% and 37\% $\Delta$ SA displayed no significant response in $\mathrm{nMSD}_{100}$ (Fig. 4). In unstretched A549 monolayers, tracking microbeads attached to A549 integrin receptors display a significant decrease in $\mathrm{nMSD}_{100}$ by $20 \mathrm{~min}$ and continuing for the duration of stretch compared with the 0 min time point (Fig. 4, also Fig. 3B). Untreated, unstretched primary AEC monolayers from the sustained tonic group displayed a similar decrease in nMSD 100 by 10 min lasting for the duration. However, unlike the progressive decrease in $\mathrm{nMSD}_{100}$ in unstretched $\mathrm{A} 549$ cells, $\mathrm{nMSD}_{100}$ in untreated unstretched primary AEC monolayers did not decline further.

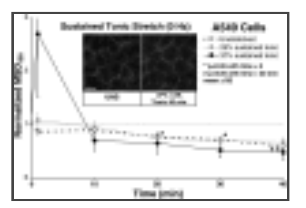

\section{Fig. 4 .}

Normalized MSD 100 (nMSD 100$)$ as a function of stretch time in A549 monolayers stretched 25\% and 37\% $\triangle$ SA held in sustained tonic $(0 \mathrm{~Hz})$ stretch or left unstretched. $\mathrm{nMSD}_{100}$ in stretched monolayers did not change significantly compared with unstretched ...

Microbead tracking specificity to actin cytoskeleton movement. To confirm that spontaneous microbead movement was specific to the reorganization of the actin cytoskeleton, additional primary AEC monolayers were incubated with microbeads coated with AcLDL, a protein complex that has been shown to bind scavenger receptors, but not focal adhesion complexes, as nonspecific control (43, 44, 64). As hypothesized, stretch of primary AEC monolayers with AcLDL-coated microbeads showed no significant change in $\mathrm{nMSD}_{100}$ compared with the unstretched time point as well as time-matched unstretched controls (Fig. 3C, inset), which similarly showed no change over time compared with time $=0 \mathrm{~min}$ (not shown). As further evidence of actin-specific binding, latrunculin-A and jasplakinolide attenuated $\mathrm{MSD}_{100}$ (previous section).

\section{DISCUSSION}

Methodological limitations. The measurement of microbead movement was restricted in three ways. First, the microbeads were attached only to the apical plasma membrane and may not have assessed actin reorganization deeper within the cell. However, type 1-like AEC monolayers are relatively flat (average thickness of $3.19 \pm 0.16 \mu \mathrm{m} \mathrm{SE}$ ). Furthermore, Hu et al. (24) tracked microbead displacements as a result of stress fiber remodeling events that were up to $30 \mu \mathrm{m}$ away from microbead center. Thus the entire actin cytoskeleton of a rat type 1-like AEC is well within the spatial sensitivity of the microbead tracking method. Second, a single microbead was attached to many surface-expressed receptors of a cell. Thus spontaneous microbead motion represented average movement of many receptors bound internally to the actin cytoskeleton. Because an ensemble of beads was tracked over a period of time, we speculate bead motion represented the summation of all actin remodeling (e.g., depolymerization, polymerization, and spatial redistribution) events in the monolayer during the 5-min observation windows. Third, measurement was limited to the actin that was attached [via talin (23)] to cell surface integrin receptors, which themselves adhere to the microbeads. Therefore, the microbead motion is an indirect measure of actin movement, and that movement may be influenced further by stress-mediated integrin-actin linkage reinforcement, previously shown in fibroblasts (13).

PJAR formation is rapid ( $<10 \mathrm{~min}$ ) and dependent on stretch magnitude and frequency. Consistent with our hypothesis, PJAR formed rapidly $(<10$ min) and was sustained (up to $60 \mathrm{~min})$ in rat type 1-like AEC monolayers at high magnitude $(25 \%$ and $37 \% \Delta \mathrm{SA})$ cyclic stretch but not at lower stretch magnitudes $(12 \% \Delta \mathrm{SA})$. Others have demonstrated comparable rapid stress fiber formation in fibroblasts (42) and endothelial cells subjected to uniaxial stretch $(25,51,63)$. Formation of PJAR was previously shown in biaxially stretched primary AEC monolayers (39) and endothelial cells (63) and postulated to be a cellular response that redistributes the actin cytoskeleton to areas of least cellular strain $(52,63)$. Consistent with this theory, we find that rapid formation of PJAR is synchronous with the increase in spontaneous microbead movement. Others report a similar rapid integrin-mediated actin movement to stretch in human airway smooth muscle (HASM) cells, where the cell immediately takes on a fluid-like behavior $(8,28,53)$. Also, Trepat et al. (53) measured cell stiffness by using optical twisting cytometry and molecular-scale structural rearrangement using the spontaneous movement of beads and found a decrease in cell stiffness and an acceleration of remodeling kinetics with transient stretch. In addition, Krishnan et al. (28) measured cell traction stress by using cell mapping rheometry and found a decrease in cell traction force following a biaxial stretch. Furthermore, we find the increase in spontaneous microbead movement was dependent on stretch magnitude and frequency. Krishnan et al. (28) and Trepat et al. (53) also showed a stretch magnitude-dependent cell response. 
With prolonged cyclic stretch, the initial spontaneous movement of microbeads was attenuated back to unstretched levels for the duration of stretch, and steady-state MSD levels were unaffected by stretch magnitude or stretch frequency. This finding suggests the mechanism of actin remodeling into PJAR took place rapidly $(<1 \mathrm{~min})$ during stretch and then ceased with sustained stretch, despite persistence of PJAR. Thus, after transient fluidization at stretch onset, the cell returns to its more solid-like state with sustained stretch, a finding similar to that after stretch release of HASM cells $(8,28,53)$. Once formed, PJAR structure may require only a baseline actin remodeling rate for maintenance of the new organization, a rate similar to the homogeneous actin structure found in unstretched monolayers. Further investigation is needed to elucidate whether rapid formation of PJAR is due to active biochemical signaling cascades, passive mechanical forces, or both.

The magnitude dependence of PJAR intensity correlates with an increase in paracellular permeability at high magnitude stretch and no change in paracellular permeability at low magnitude stretch $(9,10)$. These findings strengthen the hypothesis that the actin cytoskeleton is integral to TJ barrier maintenance in primary AEC monolayers. Others have shown PJAR and TJ are intimately linked (34) and that modification of the actin cytoskeleton results in changes in TJ-mediated paracellular permeability $(11,31,33)$. We speculate that the reorganization of actin might result in a physical separation of actin and TJ protein, thus diminishing the cellular ability to mediate paracellular permeability.

Stretch-induced PJAR formation can be inhibited with jasplakinolide and latrunculin-A. Previously, we reported that treatment with $1 \mu \mathrm{M}$ jasplakinolide reduced, but did not abolish, the stretch-induced increase in paracellular permeability in primary rat AEC monolayers stretched at $37 \% \Delta \mathrm{SA}$ (9). Here we show that we abolish formation of PJAR during stretch to $25 \% \Delta \mathrm{SA}$ by pretreating monolayers with $1 \mu \mathrm{M}$ jasplakinolide, an actin-stabilizing agent that inhibits depolymerization. In addition, treatment with latrunculin-A effectively inhibited the movement of actin-bound receptors in biaxially stretched primary AEC monolayers. Similarly, Trepat et al. used $0.1 \mu \mathrm{M}$ latrunculin-A in HASM cells and showed attenuation of stretch-induced decrease in cell stiffness $(8,53)$. Moreover Shen et al. (48) used latrunculin-A to depolymerize actin in Madin-Darby canine kidney cells, finding a reduction in transepithelial resistance within 5 min, an internalization of TJ protein occludin, and an elimination of PJAR within $20 \mathrm{~min}$. Others have demonstrated the roles of protein kinase $\mathrm{C}$ (18), adenylate cyclase (50), Rho and Rac (69), Rho-kinase (1, 26, 62), myosin light chain kinase (3, 22), and cofilin (38) on actin involvement in TJ structure and function $(22,58,59,62)$ in other stretched cell types. Whereas our results show that PJAR can be modulated, further investigation will elucidate the specific upstream pathways responsible for the formation and functional consequences of PJAR in biaxially stretched primary AEC monolayers.

Actin remodeling response depends on cell type. Unlike primary cells, A549 cell monolayers exhibited PJAR in both unstretched and stretched cell monolayers stained for F-actin. Also, the spontaneous movement of microbeads in unstretched A549 monolayers was significantly lower by $20-40 \mathrm{~min}$ compared with time $=0 \mathrm{~min}$, with $\mathrm{nMSD}_{100}$ at $40 \mathrm{~min}$ significantly less than at $20 \mathrm{~min}$. This progressive decrease in microbead movement in A549 cells, shown by others previously (54), is not found in unstretched untreated rat type 1-like AEC monolayers. The process of stiffening has been shown to exhibit a progressive decrease in microbead movement and exhibit similarities to physical aging (8), a phenomenon found in some glassy materials (46). In aging systems, molecular networks constantly advance to microconfigurations that are progressively more stable but do so at a speed that is slower than any exponential process (40). We conclude that the actin arrangement and response to stretch of A549 cells is significantly different from that in primary alveolar epithelial cells.

Summary. We have demonstrated that actin rearranges rapidly in primary AEC monolayers to form perijunctional actin ring during biaxial stretch and that formation depends on stretch magnitude and frequency. We have shown mechanistically that PJAR formation was synchronous with an increase in actin binding site movement, which was attenuated to baseline levels by 10 min. These data reveal that high-magnitude biaxial stretch within the physiological range increases the fluidity of the actin cytoskeleton, which reorganizes to form PJARs. Together with our previously published studies demonstrating that similarly large stretch magnitudes and rates adversely affect monolayer permeability $(9,14)$, we further speculate that rapid actin cytoskeleton reorganization has a deleterious effect on paracellular permeability. Future studies will investigate the effect of actin remodeling pathway inhibitors on retaining paracellular barrier properties during stretch to explore opportunities to prevent ventilator-induced lung injury.

\section{GRANTS}

This work was supported by the National Institutes of Health Grant R01-HL-057204 (to S. S. Margulies), from the University of Pennsylvania Ashton Fellowship program (to B. C. DiPaolo), and the Parker B. Francis Fellowship program (to G. Lenormand). 
No conflicts of interest, financial or otherwise, are declared by the author(s).

\section{ACKNOWLEDGMENTS}

The authors thank Yoram Lanir for role in the development of the experimental design of the MSD studies and Anirudh Lingamaneni for assisting with PJAR intensity quantification.

\section{Article information}

Am J Physiol Cell Physiol. 2010 Aug; 299(2): C345-C353.

Published online 2010 Jun 2. doi: 10.1152/ajpcell.00379.2009

PMCID: PMC2928639

Brian C. DiPaolo, ${ }^{1}$ Guillaume Lenormand, ${ }^{2}$ Jeffrey J. Fredberg, ${ }^{2}$ and Susan S. Margulies ${ }^{\bigotimes_{1}}$

${ }^{1}$ Department of Bioengineering, University of Pennsylvania, Philadelphia, Pennsylvania; and

${ }^{2}$ Molecular and Integrative Physiological Sciences, School of Public Health, Harvard University, Boston, Massachusetts

$\bigotimes_{\text {Corresponding author. }}$

Address for reprint requests and other correspondence: S. S. Margulies, Dept. of Bioengineering, Univ. of Pennsylvania, 240 Skirkanich Hall, 210 South 33 rd St., Philadelphia, PA 19104-6321 (e-mail: margulies@seas.upenn.edu).

Received 2009 Aug 21; Accepted 2010 May 28.

Copyright (C) 2010 the American Physiological Society

This article has been cited by other articles in PMC.

Articles from American Journal of Physiology - Cell Physiology are provided here courtesy of American Physiological Society

\section{REFERENCES}

1. Albinsson S, Nordstrom I, Hellstrand P. Stretch of the vascular wall induces smooth muscle differentiation by promoting actin polymerization. J Biol Chem 279: 34849-34855, 2004 [PubMed]

2. An SS, Fabry B, Mellema M, Bursac P, Gerthoffer WT, Kayyali US, Gaestel M, Shore SA, Fredberg JJ. Role of heat shock protein 27 in cytoskeletal remodeling of the airway smooth muscle cell. J Appl Physiol 96: 1701-1713, 2004 [PubMed]

3. Birukov KG, Jacobson JR, Flores AA, Ye SQ, Birukova AA, Verin AD, Garcia JG. Magnitude-dependent regulation of pulmonary endothelial cell barrier function by cyclic stretch. Am J Physiol Lung Cell Mol Physiol 285: L785-L797, 2003. [PubMed]

4. Borok Z, Danto SI, Zabski SM, Crandall ED. Defined medium for primary culture de novo of adult rat alveolar epithelial cells. In Vitro Cell Dev Biol Anim 30A: 99-104, 1994 [PubMed]

5. Bubb MR, Senderowicz AM, Sausville EA, Duncan KL, Korn ED. Jasplakinolide, a cytotoxic natural product, induces actin polymerization and competitively inhibits the binding of phalloidin to F-actin. J Biol Chem 269: 14869-14871, 1994 [PubMed]

6. Bubb MR, Spector I, Beyer BB, Fosen KM. Effects of jasplakinolide on the kinetics of actin polymerization. An explanation for certain in vivo observations. J Biol Chem 275: 5163-5170, 2000 [PubMed]

7. Bursac P, Fabry B, Trepat X, Lenormand G, Butler JP, Wang N, Fredberg JJ, An SS. Cytoskeleton dynamics: fluctuations within the network. Biochem Biophys Res Commun 355: 324-330, 2007 [PMC free article] [PubMed]

8. Bursac P, Lenormand G, Fabry B, Oliver M, Weitz DA, Viasnoff V, Butler JP, Fredberg JJ. Cytoskeletal remodelling and slow dynamics in the living cell. Nat Mater 4: 557-561, 2005 [PubMed]

9. Cavanaugh KJ, Cohen TS, Margulies SS. Stretch increases alveolar epithelial permeability to uncharged micromolecules. Am J Physiol Cell Physiol 290: C1179-C1188, 2006 [PMC free article] [PubMed] 
10. Cavanaugh KJ, Jr, Margulies SS. Measurement of stretch-induced loss of alveolar epithelial barrier integrity with a novel in vitro method. Am J Physiol Cell Physiol 283: C1801-C1808, 2002 [PubMed]

11. Cavanaugh KJ, Jr, Oswari J, Margulies SS. Role of stretch on tight junction structure in alveolar epithelial cells. Am J Respir Cell Mol Biol 25: 584-591, 2001 [PubMed]

12. Cheek JM, Evans MJ, Crandall ED. Type I cell-like morphology in tight alveolar epithelial monolayers. Exp Cell Res 184: 375-387, 1989 [PubMed]

13. Choquet D, Felsenfeld DP, Sheetz MP. Extracellular matrix rigidity causes strengthening of integrin-cytoskeleton linkages. Cell 88: 39-48, 1997 [PubMed]

14. Cohen TS, Cavanaugh KJ, Margulies SS. Frequency and peak stretch magnitude affect alveolar epithelial permeability. Eur Respir J 32: 854861,2008 [PubMed]

15. Danto SI, Zabski SM, Crandall ED. Reactivity of alveolar epithelial cells in primary culture with type I cell monoclonal antibodies. Am J Respir Cell Mol Biol 6: 296-306, 1992 [PubMed]

16. Dewey CF., Jr Effects of fluid flow on living vascular cells. J Biomech Eng 106: 31-35, 1984 [PubMed]

17. Dobbs LG, Gonzalez R, Williams MC. An improved method for isolating type II cells in high yield and purity. Am Rev Respir Dis 134: 141145, 1986 [PubMed]

18. Dwyer-Nield LD, Miller AC, Neighbors BW, Dinsdale D, Malkinson AM. Cytoskeletal architecture in mouse lung epithelial cells is regulated by protein kinase C- $\alpha$ and calpain II. Am J Physiol Lung Cell Mol Physiol 270: L526-L534, 1996 [PubMed]

19. Egan EA. Lung inflation, lung solute permeability, and alveolar edema. J Appl Physiol 53: 121-125, 1982 [PubMed]

20. Fujiwara K, Pollard TD. Fluorescent antibody localization of myosin in the cytoplasm, cleavage furrow, and mitotic spindle of human cells. J Cell Biol 71: 848-875, 1976 [PMC free article] [PubMed]

21. Haake R, Schlichtig R, Ulstad DR, Henschen Barotrauma RR. Pathophysiology, risk factors, and prevention. Chest 91: 608-613, 1987 [PubMed]

22. Hecht G, Pestic L, Nikcevic G, Koutsouris A, Tripuraneni J, Lorimer DD, Nowak G, Guerriero V, Jr, Elson EL, Lanerolle PD. Expression of the catalytic domain of myosin light chain kinase increases paracellular permeability. Am J Physiol Cell Physiol 271: C1678-C1684, 1996 [PubMed]

23. Horwitz A, Duggan K, Buck C, Beckerle MC, Burridge K. Interaction of plasma membrane fibronectin receptor with talin-a transmembrane linkage. Nature 320: 531-533, 1986 [PubMed]

24. Hu S, Chen J, Fabry B, Numaguchi Y, Gouldstone A, Ingber DE, Fredberg JJ, Butler JP, Wang N. Intracellular stress tomography reveals stress focusing and structural anisotropy in cytoskeleton of living cells. Am J Physiol Cell Physiol 285: C1082-C1090, 2003 [PubMed]

25. Iba T, Sumpio BE. Morphological response of human endothelial cells subjected to cyclic strain in vitro. Microvasc Res 42: 245-254, 1991 [PubMed]

26. Kaunas R, Nguyen P, Usami S, Chien S. Cooperative effects of Rho and mechanical stretch on stress fiber organization. Proc Natl Acad Sci USA 102: 15895-15900, 2005 [PMC free article] [PubMed]

27. Kim KJ, Crandall ED. Effects of lung inflation on alveolar epithelial solute and water transport properties. J Appl Physiol 52: 1498-1505, 1982 [PubMed]

28. Krishnan R, Park CY, Lin YC, Mead J, Jaspers RT, Trepat X, Lenormand G, Tambe D, Smolensky AV, Knoll AH, Butler JP, Fredberg JJ. Reinforcement versus fluidization in cytoskeletal mechanoresponsiveness. PLoS One 4: e5486, 2009 [PMC free article] [PubMed]

29. Lieber M, Smith B, Szakal A, Nelson-Rees W, Todaro G. A continuous tumor-cell line from a human lung carcinoma with properties of type II alveolar epithelial cells. Int J Cancer 17: 62-70, 1976 [PubMed] 
30. Liebler JM, Borok Z, Li X, Zhou B, Sandoval AJ, Kim KJ, Crandall ED. Alveolar epithelial type I cells express beta2-adrenergic receptors and G-protein receptor kinase 2. J Histochem Cytochem 52: 759-767, 2004 [PubMed]

31. Ma TY, Hollander D, Tran LT, Nguyen D, Hoa N, Bhalla D. Cytoskeletal regulation of Caco-2 intestinal monolayer paracellular permeability. J Cell Physiol 164: 533-545, 1995 [PubMed]

32. Madara JL. Intestinal absorptive cell tight junctions are linked to cytoskeleton. Am J Physiol Cell Physiol 253: C171-C175, 1987 [PubMed]

33. Madara JL, Barenberg D, Carlson S. Effects of cytochalasin D on occluding junctions of intestinal absorptive cells: further evidence that the cytoskeleton may influence paracellular permeability and junctional charge selectivity. J Cell Biol 102: 2125-2136, 1986 [PMC free article] [PubMed]

34. Madara JL, Moore R, Carlson S. Alteration of intestinal tight junction structure and permeability by cytoskeletal contraction. Am J Physiol Cell Physiol 253: C854-C861, 1987 [PubMed]

35. Maksym GN, Fabry B, Butler JP, Navajas D, Tschumperlin DJ, Laporte JD, Fredberg JJ. Mechanical properties of cultured human airway smooth muscle cells from 0.05 to $04 \mathrm{~Hz}$. J Appl Physiol 89: 1619-1632, 2000. [PubMed]

36. Margulies SS, Oswari J, Matthay MA, Tschumperlin DJ. Alveolar epithelial cytoskeleton and cell vulnerability to stretch. In: Proceedings of the American Society of Mechanical Engineers Bioengineering Division, 1999, p. 517-518

37. Mitic LL, Anderson JM. Molecular architecture of tight junctions. Annu Rev Physiol 60: 121-142, 1998 [PubMed]

38. Nagumo Y, Han J, Bellila A, Isoda H, Tanaka T. Cofilin mediates tight-junction opening by redistributing actin and tight-junction proteins. Biochem Biophys Res Commun 377: 921-925, 2008 [PubMed]

39. Oswari J, Matthay MA, Margulies SS. Keratinocyte growth factor reduces alveolar epithelial susceptibility to in vitro mechanical deformation. Am J Physiol Lung Cell Mol Physiol 281: L1068-L1077, 2001 [PubMed]

40. Parisi G. Brownian motion. Nature 433: 221, 2005 [PubMed]

41. Parker JC, Hernandez LA, Peevy KJ. Mechanisms of ventilator-induced lung injury. Crit Care Med 21: 131-143, 1993 [PubMed]

42. Pender N, McCulloch CA. Quantitation of actin polymerization in two human fibroblast sub-types responding to mechanical stretching. J Cell Sci 100: 187-193, 1991 [PubMed]

43. Plopper G, Ingber DE. Rapid induction and isolation of focal adhesion complexes. Biochem Biophys Res Commun 193: 571-578, 1993 [PubMed]

44. Puig-de-Morales M, Millet E, Fabry B, Navajas D, Wang N, Butler JP, Fredberg JJ. Cytoskeletal mechanics in adherent human airway smooth muscle cells: probe specificity and scaling of protein-protein dynamics. Am J Physiol Cell Physiol 287: C643-C654, 2004 [PubMed]

45. Qiao R, Zhou B, Liebler JM, Li X, Crandall ED, Borok Z. Identification of three genes of known function expressed by alveolar epithelial type I cells. Am J Respir Cell Mol Biol 29: 98-105, 2003 [PubMed]

46. Ramos L, Cipelletti L. Ultraslow dynamics and stress relaxation in the aging of a soft glassy system. Phys Rev Lett 87: 245503, 2001 [PubMed]

47. Raupach C, Zitterbart DP, Mierke CT, Metzner C, Muller FA, Fabry B. Stress fluctuations and motion of cytoskeletal-bound markers. Phys Rev E Stat Nonlin Soft Matter Phys 76: 011918, 2007 [PubMed]

48. Shen L, Turner JR. Actin depolymerization disrupts tight junctions via caveolae-mediated endocytosis. Mol Biol Cell 16: 3919-3936, 2005 [PMC free article] [PubMed]

49. Shikata Y, Rios A, Kawkitinarong K, DePaola N, Garcia JG, Birukov KG. Differential effects of shear stress and cyclic stretch on focal adhesion remodeling, site-specific FAK phosphorylation, and small GTPases in human lung endothelial cells. Exp Cell Res 304: 40-49, 2005 [PubMed]

50. Shirinsky VP, Antonov AS, Birukov KG, Sobolevsky AV, Romanov YA, Kabaeva NV, Antonova GN, Smirnov VN. Mechano-chemical control 
51. Takemasa T, Sugimoto K, Yamashita K. Amplitude-dependent stress fiber reorientation in early response to cyclic strain. Exp Cell Res 230: 407-410, 1997 [PubMed]

52. Takemasa T, Yamaguchi T, Yamamoto Y, Sugimoto K, Yamashita K. Oblique alignment of stress fibers in cells reduces the mechanical stress in cyclically deforming fields. Eur J Cell Biol 77: 91-99, 1998 [PubMed]

53. Trepat X, Deng L, An SS, Navajas D, Tschumperlin DJ, Gerthoffer WT, Butler JP, Fredberg JJ. Universal physical responses to stretch in the living cell. Nature 447: 592-595, 2007 [PMC free article] [PubMed]

54. Trepat X, Grabulosa M, Puig F, Maksym GN, Navajas D, Farre R. Viscoelasticity of human alveolar epithelial cells subjected to stretch. Am J Physiol Lung Cell Mol Physiol 287: L1025-L1034, 2004 [PubMed]

55. Tschumperlin DJ, Margulies SS. Equibiaxial deformation-induced injury of alveolar epithelial cells in vitro. Am J Physiol Lung Cell Mol Physiol 275: L1173-L1183, 1998 [PubMed]

56. Tschumperlin DJ, Oswari J, Margulies AS. Deformation-induced injury of alveolar epithelial cells. Effect of frequency, duration, and amplitude. Am J Respir Crit Care Med 162: 357-362, 2000 [PubMed]

57. Turner JR. "Putting the squeeze" on the tight junction: understanding cytoskeletal regulation. Semin Cell Dev Biol 11: 301-308, 2000 [PubMed]

58. Turner JR, Angle JM, Black ED, Joyal JL, Sacks DB, Madara JL. PKC-dependent regulation of transepithelial resistance: roles of MLC and MLC kinase. Am J Physiol Cell Physiol 277: C554-C562, 1999 [PubMed]

59. Turner JR, Rill BK, Carlson SL, Carnes D, Kerner R, Mrsny RJ, Madara JL. Physiological regulation of epithelial tight junctions is associated with myosin light-chain phosphorylation. Am J Physiol Cell Physiol 273: C1378-C1385, 1997 [PubMed]

60. van der Flier A, Sonnenberg A. Function and interactions of integrins. Cell Tissue Res 305: 285-298, 2001 [PubMed]

61. Van Itallie CM, Anderson JM. Occludin confers adhesiveness when expressed in fibroblasts. J Cell Sci 110: 1113-1121, 1997 [PubMed]

62. Walsh SV, Hopkins AM, Chen J, Narumiya S, Parkos CA, Nusrat A. Rho kinase regulates tight junction function and is necessary for tight junction assembly in polarized intestinal epithelia. Gastroenterology 121: 566-579, 2001 [PubMed]

63. Wang JH, Goldschmidt-Clermont P, Wille J, Yin FC. Specificity of endothelial cell reorientation in response to cyclic mechanical stretching. J Biomech 34: 1563-1572, 2001 [PubMed]

64. Wang N, Butler JP, Ingber DE. Mechanotransduction across the cell surface and through the cytoskeleton. Science 260: 1124-1127, 1993 [PubMed]

65. Ware LB, Matthay MA. The acute respiratory distress syndrome. N Engl J Med 342: 1334-1349, 2000 [PubMed]

66. Wechezak AR, Viggers RF, Sauvage LR. Fibronectin and F-actin redistribution in cultured endothelial cells exposed to shear stress. Lab Invest 53: 639-647, 1985 [PubMed]

67. White GE, Gimbrone MA, Jr, Fujiwara K. Factors influencing the expression of stress fibers in vascular endothelial cells in situ. J Cell Biol 97: 416-424, 1983 [PMC free article] [PubMed]

68. Wiesner S, Legate KR, Fassler R. Integrin-actin interactions. Cell Mol Life Sci 62: 1081-1099, 2005 [PubMed]

69. Wojciak-Stothard B, Potempa S, Eichholtz T, Ridley AJ. Rho and Rac but not Cdc42 regulate endothelial cell permeability. J Cell Sci 114: 1343-1355, 2001 [PubMed]

70. Yarmola EG, Somasundaram T, Boring TA, Spector I, Bubb MR. Actin-latrunculin A structure and function. Differential modulation of actinbinding protein function by latrunculin A. J Biol Chem 275: 28120-28127, 2000 [PubMed] 